\title{
Potential of Slip Synchronous Wind Turbine Systems: Grid Support and Mechanical Load Mitigation
}

\author{
Dillan Kyle Ockhuis *(D) and Maarten Kamper
}

Department of Electrical and Electronic Engineering, Stellenbosch University, Stellenbosch 7600, South Africa; kamper@sun.ac.za

* Correspondence: d.ockhuis09@gmail.com

Citation: Ockhuis, D.K.; Kamper, M. Potential of Slip Synchronous Wind Turbine Systems: Grid Support and Mechanical Load Mitigation. Energies 2021, 14, 4995. https://doi.org/ 10.3390/en14164995

Academic Editor: Clemens Jauch

Received: 25 June 2021

Accepted: 6 August 2021

Published: 14 August 2021

Publisher's Note: MDPI stays neutral with regard to jurisdictional claims in published maps and institutional affiliations.

Copyright: (c) 2021 by the authors. Licensee MDPI, Basel, Switzerland. This article is an open access article distributed under the terms and conditions of the Creative Commons Attribution (CC BY) license (https:/ / creativecommons.org/licenses/by/ $4.0 /)$.

\begin{abstract}
Wind power penetration into existing electrical power systems continues to experience year-on-year growth. Consequently, modern wind turbine systems (WTS) are required to comply with relevant grid codes and provide ancillary grid services to assist with overall grid stability. Adhering to these grid codes and services can cause additional mechanical loading on WTS, which can result in a reduction in service life of some of the drivetrain components, and instability if a sufficient means of damping is not present in the drivetrain. In this paper, a dynamic simulation model of a Type 1, direct grid-connected, fixed-speed (FS) slip-synchronous wind turbine system (SS-WTS) is developed to investigate its dynamic stability in response to the additional mechanical loads imparted onto it during transient events on the grid. The SS-WTS is not equipped with a power converter and, consequently, an understanding of its dynamic stability is critical to evaluate its ability to assist with grid services and maintain stability during transient grid conditions such as low-voltage ride-through (LVRT) events. An analytical transfer function model of a $1.5 \mathrm{MW}$ geared direct grid-connected SS-WTS was derived and implemented in MATLAB/Simulink. It was found that the SS technology provides significant damping to the WTS drivetrain while maintaining dynamic stability during a severe LVRT event. Moreover, it was found that the degree of damping is directly proportional to the value of rated slip, and that high-speed drivetrains provide a greater degree of damping for a given value of rated slip. Furthermore, it is shown that the SS-WTS has the ability to assist with grid services such as primary frequency response, short-circuit strength, and reactive power compensation.
\end{abstract}

Keywords: wind power generation; grid services; stability; power systems; short-circuit strength

\section{Introduction}

Wind energy remains one of the fastest growing renewable energy markets worldwide, with annual installations surpassing $93 \mathrm{GW}$ in 2020 while showing a year-on-year growth rate of $53 \%$ [1,2]. Furthermore, a combined $469 \mathrm{GW}$ of both onshore and offshore wind capacity is to be installed in the period from 2021 to 2025 . One of the main drivers of the continued growth of wind turbine installations is the United Nation's call for urgent action to reach net zero greenhouse gas emissions by 2050 in an attempt to prevent a rise in the average global temperature of more than $2{ }^{\circ} \mathrm{C}$. To reach these targets, it has been proposed that traditional fossil-fuel based generators be phased out, in conjunction with a significant increase in renewable energy generation and infrastructure.

The rapid increase in penetration levels of renewable energy sources has prompted transmission system operators (TSO) to update their grid connection codes with specific requirements pertaining to wind generators and wind farms, with the aim of maintaining and ensuring reliable grid performance and stability, whereas wind turbine systems (WTS) previously could simply disconnect from the grid during adverse grid anomalies. However, as the proportion of wind energy penetration increases, simply disconnecting large wind farms from the grid could result in a significant imbalance between energy supply and 
demand, which has the potential to cause large excursions in the grid frequency and can result in local or nationwide loadshedding events or, as a worst-case scenario, blackouts [3]. As a result of these grid code changes, modern WTS and wind farms are expected to operate as conventional power plants and support the grid by providing ancillary grid services, such as frequency regulation, active power regulation, reactive power support, and low-voltage ride-through (LVRT) capabilities [4-7]. Consequently, most modern WTS are equipped with either a partially-rated (Type 3) or a full-rated (Type 4) power electronic converter (PEC), which is responsible for ensuring that the WTS adheres to the relevant grid codes and maintains stability.

The ability of Type 3 and Type 4 WTS to provide ancillary support to the grid by means of active power and frequency regulation [8-13] and reactive power regulation [14,15] is understood well. Furthermore, they are capable of providing inertial (frequency) support to the grid in the form of synthetic inertia, whereby the PEC extracts the kinetic energy from the WTS rotor. However, this is usually only for a relatively short period of time and requires sophisticated coordination between the PEC's controllers [16]. However, their ability to provide sufficient short-circuit current (SCC) during LVRT events and grid faults is limited by the current rating of their respective converters [17]. The ability of a WTS to provide sufficient SCC is critical for improving the overall grid strength for proper grid protection. Type 4 WTS, which are equipped with a full-rated converter, can typically only supply a maximum short-circuit current of 1.2 per-unit of the generator's rated current. This is insufficient current for existing grid-protection schemes. Moreover, as the ratio of inverter-tied renewable energy sources versus traditional, direct-tied synchronous generators (SGs) increases, future power systems may experience a further reduction in short-circuit strength (SCS) due to the lack of rotational inertia present in the system $[17,18]$. This poses a problem in the weaker areas of a power system, because a low SCS results in that area of the power system being more susceptible to voltage and frequency instability caused by changes in load or faults. It has been proposed and shown in [19] that placing synchronous condensers (SCs) at strategic points within a power system that contains wind farms consisting of Type 4 WTS has the effect of improving the fault ride-through performance of the power system. This is because SCs are capable of supplying relatively large short-circuit current in the event of faults, thus increasing the SCS of the power system.

In an attempt to have SG-based renewable energy (RE) systems (instead of, or in tandem with, the growing inverter-based RE systems), where the SGs are connected directly to the grid, the so-called slip-synchronous wind turbine system (SS-WTS) was proposed. The originally proposed SS-WTS is a fixed-speed system that consists of a slip-permanent magnetic coupling (S-PMC) situated between the wind turbine and a directdrive permanent magnet SG (PMSG), where the latter is directly connected to the grid without a full-rated PEC [20,21]. The S-PMC allows the PMSG to be connected directly to the grid without the need for damper windings by providing mechanical damping in the form of slip, typically between $1 \%$ and $3 \%$.

In recent years, it has been proposed that the conventional PMSG used in [20] be replaced with a hybrid PMSG, whereby field-coil windings are integrated into the PM rotor design, either in series [22] or in parallel [23]. The inclusion of the field-coil windings would allow for variable-flux operation, which, in conjunction with a blade-pitch control system, would make the SS-WTS grid code compliant. In this sense, the SS-WTS has the added ability to act as a type of SC during low-wind conditions by still providing valuable grid services, such as reactive power compensation and power system SCS.

However, without a PEC, the SS-WTS has no means of actively damping the drivetrain torque pulsations caused by the wind, or those originating from the grid. It is shown in [24] that the S-PMC provides excellent damping to a direct-drive SS drivetrain against pulsating wind conditions and tower-shadowing effects, which would otherwise cause torque pulsations within the drivetrain. However, for geared SS-WTS [25], it is critical that the S-PMC provides sufficient damping to the drivetrain to protect the gearbox against sudden changes in load and grid faults. During a grid fault, the generator experiences a 
sudden change in voltage at its terminals and, depending on the severity of the change in voltage, the generator will undergo a transient in its electromagnetic torque. This transient torque can result in significant stress being placed on the mechanical drivetrain components of the wind turbine [26]. Moreover, providing sufficient damping to the drivetrain is important for protecting the drivetrain gearbox, as it has been shown in $[27,28]$ that torque pulsations can reduce the lifetime of the gearbox. Consequently, protecting the gearbox is of utmost importance, as it is one of the most expensive drivetrain components and is responsible for the longest periods of downtime [29].

Traditional Type 1, fixed-speed, direct-grid connected WTS are characterized as being unable to provide support to the grid during significant fault conditions due to their limited fault-ride-through capabilities. Furthermore, PMSG-based WTS cannot be directly connected to the grid (without damper windings or a PEC) due to the inherent lack of damping within these drivetrains. The contribution of this paper is therefore to propose an analytical simulation model of the proposed Type 1, fixed-speed, direct grid-connected SS-PMSG, to demonstrate and analyse its dynamic stability during a severe LVRT event. To achieve this, the direct grid-connected SS-WTS's transfer function is derived and the damping effect of the S-PMC on the transfer function is investigated. Moreover, the influence of the combination of the S-PMC and the inertia of the generator on the overall system stability is analysed.

A 1.5 MW, geared SS-WTS is modelled in MATLAB/Simulink, whereby the SS-WTS is connected to a grid whose frequency and voltage are variable. The simulation model is used to illustrate the potential for SS-WTS to provide grid services in the form of primary frequency support, SCS, and reactive power support. Furthermore, we evaluate the effect of mechanical loading resulting from these grid services, specifically LVRT events.

\section{Dynamic Stability of Direct Grid-Connected PMSG WTS}

In this section, a mathematical model of a direct grid-connected SS-WTS is developed. The section starts by deriving a classical simplified transfer function of a conventional grid-tied PMSG, followed by the derivation of a transfer function of the SS-WTS in order to illustrate the importance of the S-PMC for direct grid-connected PMSGs.

\subsection{Direct Grid-Connected PMSG}

Figure 1a shows a line diagram model of a geared WTS with a direct grid-connected PMSG. Following classical analysis, the developed power $\left(P_{S}\right)$ and torque $\left(T_{S}\right)$ of the PMSG can be expressed respectively as

$$
P_{s}=\frac{E_{s} V_{s}}{X_{s}} \sin (\delta) \quad \text { and } \quad T_{s}=\frac{E_{s} V_{s}}{\omega_{s m} X_{s}} \sin (\delta),
$$

where $E_{S}$ and $V_{s}$ are the back-electromotive force (back-emf) voltage and line-voltage respectively, and $X_{S}$ is the synchronous reactance of the PMSG. Additionally, in (1), $\omega_{s m}$ is the synchronous angular velocity and $\delta$ is the power angle between $E_{S}$ and $V_{s}$. If we assume $V_{s} \approx E_{s}=\sqrt{2} \pi f_{s} N_{s} \phi_{s}$, and with $X_{s}=2 \pi f_{s} L_{s}$, then at low loads (small values of $\delta$ ) the developed torque can further be approximated as

$$
T_{s} \approx \frac{3 p N_{s}^{2} \phi_{s}^{2}}{4 L_{S}} \delta=K_{s} \delta
$$

where $p$ is the number of poles, $N_{S}$ is the SG's effective number of turns in series per-phase, $\phi_{S}$ is the flux per pole of the PMSG, and $L_{S}$ is the per-phase inductance. The drivetrain dynamics of the direct grid-connected PMSG can be described as

$$
T_{t}^{\prime}-T_{s}=J_{t}^{\prime} \frac{d \omega_{t}^{\prime}}{d_{t}} \quad \text { and } \quad \omega_{t}^{\prime}-\omega_{s m}=\frac{d \delta_{m}}{d_{t}},
$$


where $\omega_{t}^{\prime}$ is the angular velocity of the wind turbine reflected across the gearbox (GB) and $\omega_{s m}=\frac{4 \pi f_{s}}{p}$ is the synchronous angular velocity of the direct grid-connected PMSG, with $f_{s}$ being the frequency of the grid. Furthermore, $J_{t}^{\prime}=J_{t} / G B^{2}$ is the inertia of the turbine reflected across the gearbox plus the rotational inertia of the PMSG, whereas $T_{t}^{\prime}=T_{t} / G B$ is the turbine torque reflected across the gearbox. Additionally, $\delta_{m}=\frac{2}{p} \delta$ is the mechanical power angle.

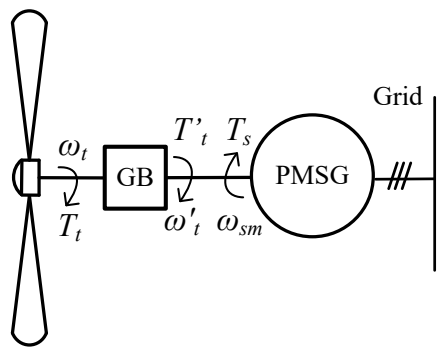

(a)

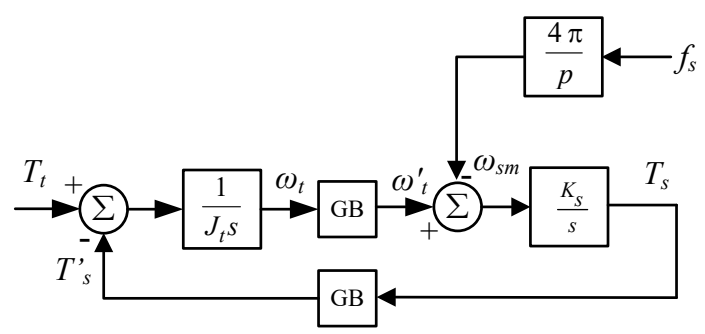

(b)

Figure 1. Simplified (a) line diagram representation model and (b) block diagram model of a direct grid-connected, geared PMSG WTS.

From Equations (1)-(3), a simplified block diagram model of the direct grid-connected PMSG was derived and is shown in Figure 1b, where the input to the block model is the turbine torque, $T_{t}$, and the output is the developed PMSG torque, $T_{s}$. It can be shown from classical textbook analysis that a second-order transfer function model that describes the torque dynamics of the system can be derived as

$$
\frac{T_{s}(s)}{T_{t}^{\prime}(s)}=\frac{\frac{K_{s}}{J_{t}^{\prime}}}{s^{2}+\frac{K_{s}}{J_{t}^{\prime}}} .
$$

From (4) it can be seen that the second-order transfer function of the direct gridconnected PMSG WTS has poles that lie on the imaginary axis of the s-plain. This means that a step-change in $T_{t}^{\prime}(s)$ will result in an undamped and oscillatory PMSG torque (output) response $T_{S}$, which will continue to oscillate indefinitely. Consequently, the direct grid-connected PMSG is treated as an unstable system.

\subsection{Direct Grid-Connected SS-PMSG}

The same modelling procedure used to model the direct-grid connected PMSG was used to model the direct grid-connected SS-PMSG. A simplified line diagram of the SSPMSG is shown in Figure 2a. Here it can be seen that the S-PMC is placed between the gearbox and the PMSG. The resulting block diagram transfer-function model of the SS-PMSG WTS is shown in Figure $2 b$.

The S-PMC in an SS-WTS is a magnetic coupling consisting of two rotating sections, where one of the sections contains PMs and the other section consists of individually short-circuited coils. The S-PMC transfers the torque of the geared turbine to the generator by means of electromagnetic induction due to the relative difference in speed between the two rotating sections. The difference in speed between the rotating sections is referred to as slip (ऽ), which is defined as

$$
\varsigma=\frac{\omega_{t}^{\prime}-\omega_{m}}{\omega_{m}} .
$$


With reference to Figure $2 \mathrm{~b}$, the slip speed is given as $\omega_{s l}=\omega_{t}^{\prime}-\omega_{m}=\varsigma \omega_{m}$. Moreover, the efficiency of the S-PMC is given by

$$
\eta=\frac{\omega_{m}}{\omega_{t}^{\prime}}=\frac{1}{1+\varsigma}
$$
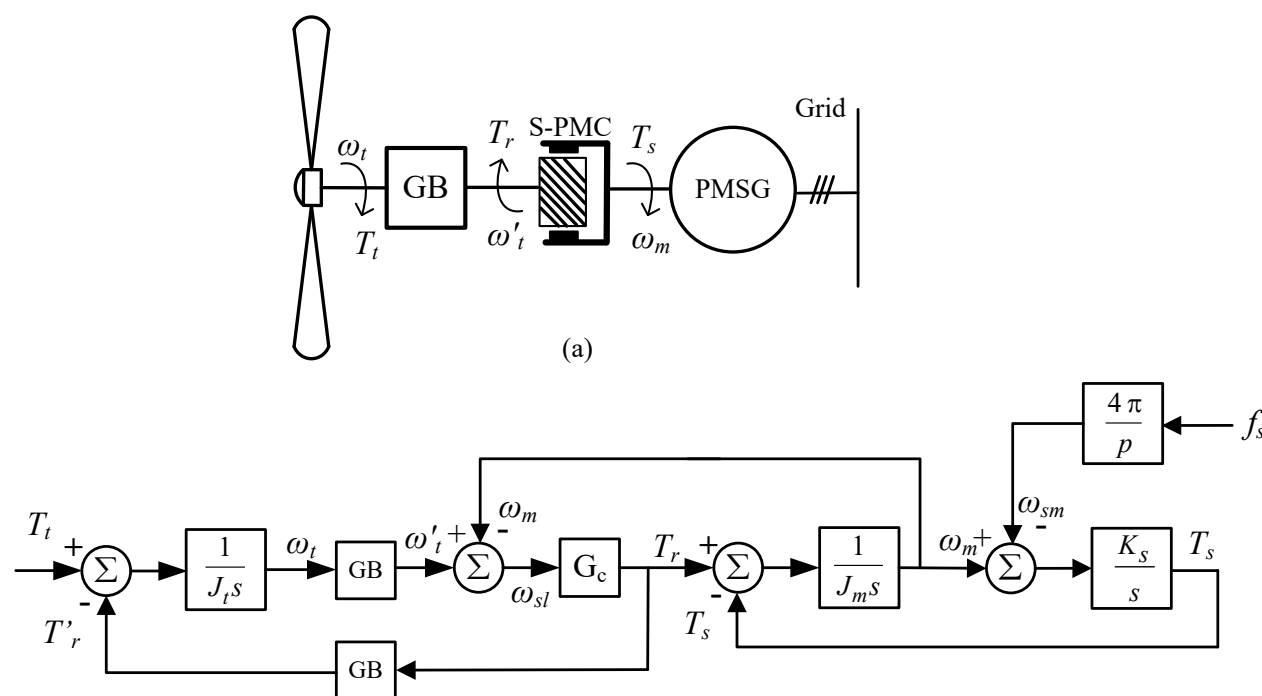

(b)

Figure 2. Simplified (a) line diagram representation model and (b) block diagram model of a geared SS-PMSG WTS.

With reference to (6), the S-PMC's efficiency is inversely proportional to slip. When considering that WTSs rarely operate at rated conditions, the S-PMC operates at near 100\% efficiency for extended periods of time at average power conditions.

Due to the linear nature of the torque developed by the S-PMC $\left(T_{r}\right)$ and the slip speed $\left(\omega_{s l}\right)$, the S-PMC can be modelled as a gain of which the value is determined by

$$
G_{c}=\frac{T_{r}}{\omega_{s l}}
$$

It should be noted that (7) is typically only valid in the slip range of $\varsigma<3$ pu.

The dynamics of the direct grid-connected SS-PMSG of Figure 2 is given as

$$
T_{t}^{\prime}-T_{r}=J_{t}^{\prime} \frac{d \omega_{t}^{\prime}}{d t}
$$

whereas the dynamics of the S-PMC's PM rotor and the rotor of the PMSG are given by

$$
T_{r}-T_{s}=J_{m} \frac{d \omega_{m}}{d t}
$$

where $J_{m}$ is the inertia of the PMSG plus S-PMC respectively.

From the block diagram model of Figure $2 b$, a transfer function model of the SS-PMSG WTS can be derived as

$$
\frac{T_{s}(s)}{T_{t}^{\prime}(s)}=\frac{K_{s} G_{c}}{J_{m} J_{t}^{\prime} s^{3}+G_{c} J_{m} s^{2}+K_{s} J_{t}^{\prime} s+G_{c} K_{s}} .
$$

Since the coefficients of the third-order transfer function of (10) are all positive, the transfer function will only have negative roots (poles) in the s-plain, which means that the direct grid-connected SS-PMSG system is inherently stable. 


\section{Modelling}

In this section, a more sophisticated analytical model of the SS-WTS and the grid is developed. The developed model is used in the following section to simulate the dynamic response and stability of the direct grid-connected SS-WTS during various disturbances resulting from the grid.

\subsection{Grid Model}

To evaluate the on-grid dynamics of the SS-WTS, a more sophisticated model of the grid and PMSG is required. The grid is modelled as a large synchronous generator (SG) which is equipped with load frequency control. The grid supplies a balanced set of threephase voltages, $v_{a b c}$ and a variable grid frequency, $f_{s}$. The grid frequency is governed by the swing equation, which is given in classical texts as

$$
P_{m(p u)}-P_{e(p u)}-D\left(\omega_{p u}-\omega_{s y n}\right)=\frac{2 H}{\omega_{s y n}} \omega \frac{d \omega}{d t},
$$

where $P_{m(p u)}$ is the mechanical power supplied by the SG's prime mover and $P_{e(p u)}$ is the electrical output power of the generator, both in per unit (pu). The angular velocity of the SG's rotor is given by $\omega$, and $\omega_{\text {syn }}$ is the synchronous angular velocity. The inertia constant of the grid is given by $H$, and $D$ is a torque-damping term. It was shown in [30] that after a disturbance, (11) can be written in terms of a small-signal model as

$$
\Delta P_{m}-\Delta P_{e}+\Delta P_{s}-D \Delta \omega=2 H \frac{\Delta \omega}{d t} .
$$

In (12), the term $\Delta P_{S}$ is included to represent the additional supply power of the grid-connected SS-WTS. In the grid model considered here, the mechanical output power of the generator is controlled by a simple turbine-governor controller, which is described by

$$
\Delta P_{m(p u)}=\Delta P_{r e f(p u)}-\frac{1}{R} \Delta f,
$$

where $\Delta f$ is the change in frequency, $\Delta P_{r e f(p u)}$ is a change in the reference power setting, and $R$ is a regulating constant. Figure 3 shows a block diagram representation of Equations (11)-(13), where $T_{G}, T_{R H}$, and $T_{C H}$ are the respective governor, re-heat, and steam-flow time constants of the turbine driving the SG's prime mover.

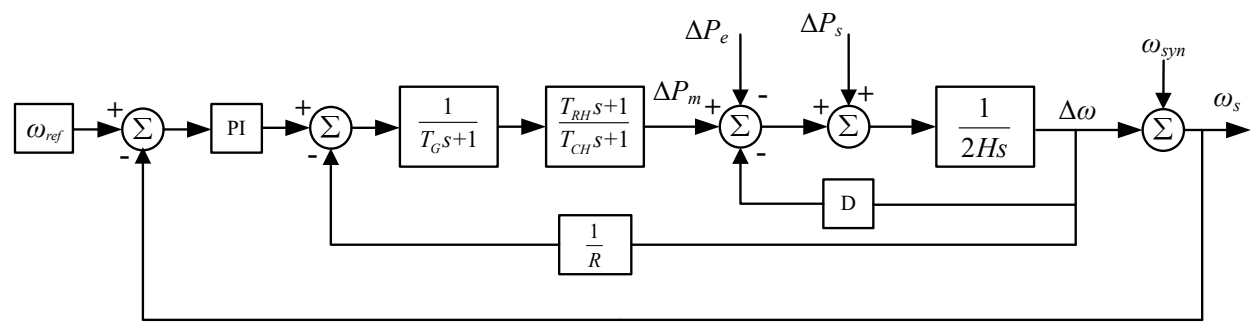

Figure 3. Block diagram model of a power system grid with load frequency control.

\subsection{SS-WTS Model}

The PMSG model of (2) is replaced with a $d q$ reference frame dynamic model of the generator without damper windings, described by

$$
\begin{aligned}
& v_{d s}=-R_{s} i_{d s}-L_{d s} \frac{d i_{d s}}{d t}+\omega_{e} L_{q s} i_{q s} \\
& v_{q s}=-R_{s} i_{q s}-L_{q s} \frac{d i_{q s}}{d t}-\omega_{s} L_{d s} i_{d s}+\omega_{e} \lambda_{m s}
\end{aligned}
$$


where $v_{d q}$ are the terminal voltages of the direct grid-connected PMSG and $i_{d q}$ are the $d q$-axis currents. The per-phase inductances are given by $L_{d s}$ and $L_{q s}$ respectively, and the perphase armature winding resistance is given as $R_{s}$. The flux linkage due to the permanent magnets is given by $\lambda_{m s}$, and $\omega_{e}$ is the electrical angular speed.

The respective electromagnetic torque, power, and reactive power of the PMSG are given by

$$
\begin{gathered}
T_{s}=\frac{3}{4} p\left[\left(L_{q s}-L_{d s}\right) i_{d s} i_{q s}+\lambda_{m s} i_{q s}\right], \\
P_{s}=\frac{3}{2}\left(v_{d s} i_{d s}+v_{q s} i_{q s}\right) \quad \text { and } \quad Q_{s}=\frac{3}{2}\left(v_{q s} i_{d s}-v_{d s} i_{q s}\right) .
\end{gathered}
$$

The block diagram model of the direct grid-connected SS-WTS of Figure $2 b$ is replaced by the block diagram model shown in Figure 4. The grid is modelled as a voltage source that produces a balanced set of three-phase voltages, $v_{a b c}$, which are transformed into the $d q$ reference frame by means of the Park transformation. The resulting $d q$ voltages, $v_{d q}$, are used in conjunction with (14) and (15) to produce the torque and current response of the SS-WTS.

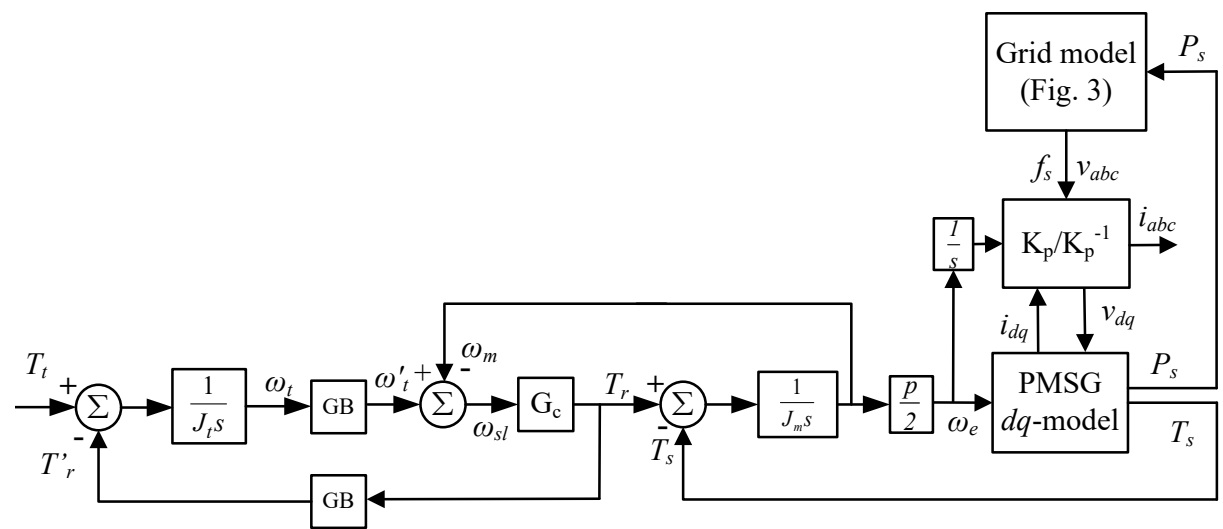

Figure 4. Block diagram model of a geared, direct grid-connected SS-PMSG WTS.

\subsection{PMSG under Short-Circuit Conditions}

It can be shown from classical texts [31] that the $d q$ currents of (14) and torque of (15) during a short circuit can be approximated as

$$
\begin{aligned}
& i_{d s s}(t) \approx \frac{-E_{q}}{x_{d s}}-E_{q}\left(\frac{1}{x_{d}^{\prime \prime}}-\frac{1}{x_{d}^{\prime}}\right) e^{\frac{-t}{T_{d}^{\prime \prime}}}-\frac{E_{q}}{x_{d}^{\prime \prime}} e^{\frac{-t}{T_{a}}} \cos \left(\omega_{e} t\right), \\
& i_{q s s}(t) \approx \frac{-E_{q}}{x_{q s}} e^{\frac{-t}{T_{a}}}\left(\sin \omega_{e} t\right),
\end{aligned}
$$

and

$$
\begin{aligned}
T_{s s}(t) & \approx \frac{3 p}{4 \omega_{e}}\left\{E_{q}^{2} e^{\frac{-t}{T_{a}}}\left[\frac{1}{x_{d s}}+\left(\frac{1}{x_{d}^{\prime}}-\frac{1}{x_{d s}}\right) e^{\frac{-t}{T_{d}^{\prime}}}+\left(\frac{1}{x_{d}^{\prime \prime}}-\frac{1}{x_{d}^{\prime}}\right) e^{\frac{-t}{T_{d}^{\prime \prime}}}\right] \sin \omega_{e} t\right. \\
& \left.+\frac{E_{q}^{2}}{2} e^{\frac{-2 t}{T_{a}}}\left(\frac{1}{x_{d}^{\prime \prime}}-\frac{1}{x_{q}^{\prime \prime}}\right) \sin 2 \omega_{e} t\right\} .
\end{aligned}
$$

In (17) and (18), $x_{d s}=\omega_{e} L_{d s}$ and $x_{q s}=\omega_{e} L_{q s}$ are the $d q$-axis synchronous reactances, $x_{d}^{\prime}$ is the transient reactance, and $x_{d q}^{\prime \prime}$ are the $d q$ subtransient reactances respectively. Moreover, $E_{q}=\omega_{e} \lambda_{m s}$ is the open-circuit back-emf of the PMSG, and the symbol $T$ denotes the respective time constants associated with the short-circuit condition.

When considering that PM machines do not have field windings, the transient reactance, $x_{d}^{\prime}$, and the associated transient time constant, $T_{d}^{\prime}$, are not defined. However, 
as shown in [32], the transient parameters are represented by setting $x_{d}^{\prime}=x_{d s}$ and $T_{d}^{\prime}=T_{d}^{\prime \prime}$, where $T_{d}^{\prime \prime}$ is the subtransient time constant. Furthermore, segmenting the PM poles of a synchronous machine is typically done to reduce induced eddy currents in the PM material, thereby reducing the overall losses. It is shown in [32] that, as the number of segments per PM pole increases, $x_{d}^{\prime \prime} \approx x_{d s}$ and, as a result, the middle term in (17) for the $d$-axis short-circuit current, and the two exponential terms in the square brackets in (18) are zero. Finally, the PMSG considered here is equipped with a round rotor with surface-mounted PMs, such that $x_{d s}=x_{q s} \approx x_{d q}^{\prime \prime}$ and, as a result, the double-frequency term in (18) is zero. Consequently, the torque appearing at the short circuit is approximately

$$
T_{s S}(t) \approx \frac{3 p}{4 \omega_{e}}\left[\frac{E_{q}^{2}}{x_{d s}} e^{\frac{-t}{T_{a}}} \sin \left(\omega_{e} t\right)\right]
$$

where $T_{a}$ is the armature (stator) transient time constant, defined as

$$
T_{a}=\frac{2}{R_{s}\left(\frac{1}{L_{q s}}+\frac{1}{L_{d s}}\right)} .
$$

Equation (19) shows that the short-circuit torque for a direct grid-connected PMSG is a sinusoidal function with a large amplitude that is inversely proportional to $x_{d s}$ and swings from positive to negative. This sudden and large torque reversal indicates that a high degree of sheering stress will be placed on the rotor shaft and gear teeth of the drivetrain gearbox. Hence, this has the potential to damage the drivetrain gearbox if $T_{S S}$ is not dampened sufficiently [26].

\subsection{Torque-Damping Effect of the S-PMC and PMSG}

Short-circuit and LVRT conditions are some of the most severe grid-fault conditions a WTS must endure. Furthermore, the gearbox is one of the most expensive drivetrain components and is responsible for the longest periods of downtime [33,34]. In this section, the block diagram model of Figure 4 is used to derive a transfer function representation of the grid-connected SS-WTS to investigate its ability to dampen drivetrain torque pulsations induced by the grid.

Figure 5 shows a section of the block diagram of Figure 4 where, in this case, we are interested in the relationship between the generator torque, $T_{s}$, and the torque of the S-PMC, $T_{r}$. In Figure 5, the input is $T_{s}$ and the output is $T_{r}$. The relationship between $T_{s}$ and $T_{r}$ gives an indication of the S-PMC's ability to filter the torque transients produced by the PMSG, which ultimately penetrate the drivetrain gearbox. From Figure 5, a classical transfer function model can be derived as

$$
\frac{T_{r}(s)}{T_{s}(s)} \approx \frac{\frac{G_{c}}{J_{m}}}{s+\frac{G_{c}}{J_{m}}} .
$$

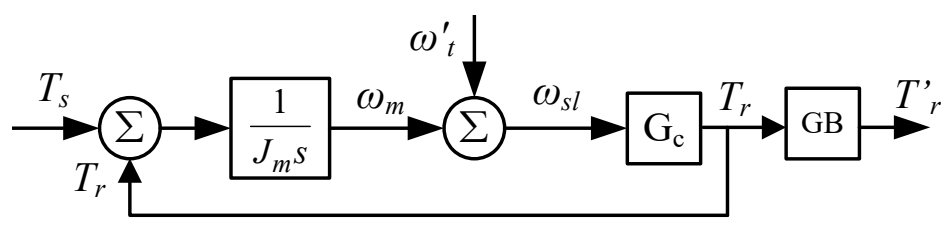

Figure 5. Block diagram model illustratrating the relationship between the torque of the PMSG and the torque of the S-PMC in an SS-WTS (see Figure 4).

Equation (21) shows that the relationship between $T_{s}$ and $T_{r}$ is that of a low-pass filter with a cut-off frequency of

$$
f_{c} \approx \frac{G_{c}}{2 \pi J_{m}} .
$$


Furthermore, (22) indicates that the filtering response of the SS-WTS depends on the ratio of the gain of the S-PMC $G_{\mathcal{C}}$, and the inertia of the PMSG, $J_{m}$. Moreover, from (19) we see that the frequency of the short-circuit torque of a surface-mount PMSG (assuming segmented magnet poles) is that of the grid frequency, $f_{s}$. Consequently, the magnitude of the short-circuit torque response produced by the PMSG will be attenuated by a factor of

$$
A_{f}=20 \log \left(\frac{f_{c}}{f_{s}}\right) \quad \mathrm{dB} .
$$

Equations (7), (22) and (23) can thus be used to design an S-PMC for a given PMSG to dampen the magnitude of torque transients resulting from the PMSG during a LVRT event.

\section{Simulation Results}

In this section, the dynamic stability models developed in the previous sections were transferred to MATLAB/Simulink in order to investigate the dynamic behaviour of the direct grid-connected SS-WTS. The simulation was conducted on a 1.5 MW power level, and Table 1 gives the simulation parameters used in the investigation. During the simulation, the considered SS-WTS was operating under a 0.5 per-unit torque input. Furthermore, the $d q$ synchronous reactance, $x_{d q}$, in Table 1 is the reactance of the PMSG plus an additional series-line reactance (SLR), as is recommended in [35] to reduce the sensitivity of the PMSG to variations in grid voltage.

Table 1. SS-WTS and grid simulation parameters.

\begin{tabular}{cccc}
\hline SS-WTS Parameter & Value & Grid Parameter & Value \\
\hline Rated power $\left(P_{\text {rated }}\right)$ & $1.5 \mathrm{MW}$ & Rated frequency & $50 \mathrm{~Hz}$ \\
Synchronous speed $\left(n_{s}\right)$ & $1500 \mathrm{rpm}$ & Line voltage $(1.0 \mathrm{pu})$ & $690 \mathrm{~V}$ \\
Pole number $(p)$ & 4 & Governor time constant $\left(T_{G}\right)$ & $0.1 \mathrm{~s}$ \\
S-PMC gain $\left(G_{c}\right)$ & 6085 & Steam flow time constant $\left(T_{C H}\right)$ & $0.2 \mathrm{~s}$ \\
Turbine inertia $\left(J_{t}\right)$ & $6 \times 10^{6} \mathrm{~kg} \cdot \mathrm{m}^{2}$ & Re-heat time constant $\left(T_{R H}\right)$ & $7 \mathrm{~s}$ \\
Generator inertia $\left(J_{m}\right)$ & $144 \mathrm{~kg} \cdot \mathrm{m}^{2}$ & Grid inertia constant $(H)$ & $10 \mathrm{~s}$ \\
Gear ratio $(\mathrm{GB})$ & 83 & Damping coefficient $(D)$ & 1 \\
Synchronous reactance $\left(x_{d q}\right)$ & $0.5 \mathrm{pu}$ & Proportional gain $(\mathrm{P})$ & 10 \\
Stator resistance $\left(R_{s}\right)$ & $0.035 \mathrm{pu}$ & Integral gain $(\mathrm{I})$ & 2 \\
Percentage rated slip $(\varsigma)$ & $1 \%$ & Regulating constant $(R)$ & 0.05 \\
\hline
\end{tabular}

\subsection{LVRT Dynamic Response}

Figure 6 shows an example of a severe low-voltage ride-through (LVRT) condition for wind turbines. For this LVRT condition, Figure 7 shows the torque response of the PMSG $\left(T_{S}\right)$ and that of the S-PMC $\left(T_{r}\right)$ during the time period $t=1.98$ to $2.22 \mathrm{~s}$. With reference to (22), Table 1, and Figure 8, which shows the transfer function frequency response, $T_{r}(s) / T_{S}(s)$, of the considered SS-WTS, it is clear that the ratio of the S-PMC gain and the inertia of the PMSG has the effect of attenuating the $50 \mathrm{~Hz}$ torque transient of the generator by the attenuation factor of (23). 


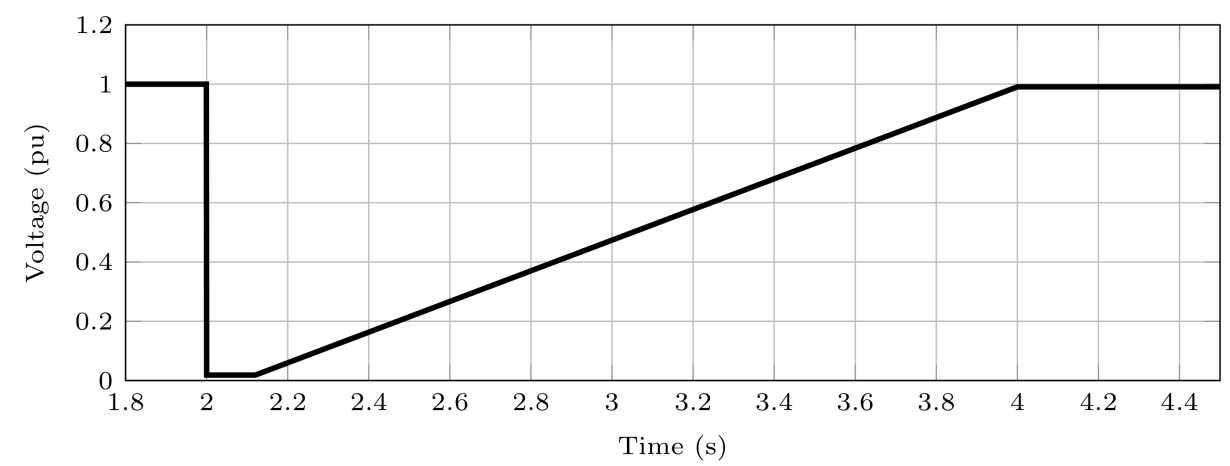

Figure 6. LVRT condition for wind turbine systems.

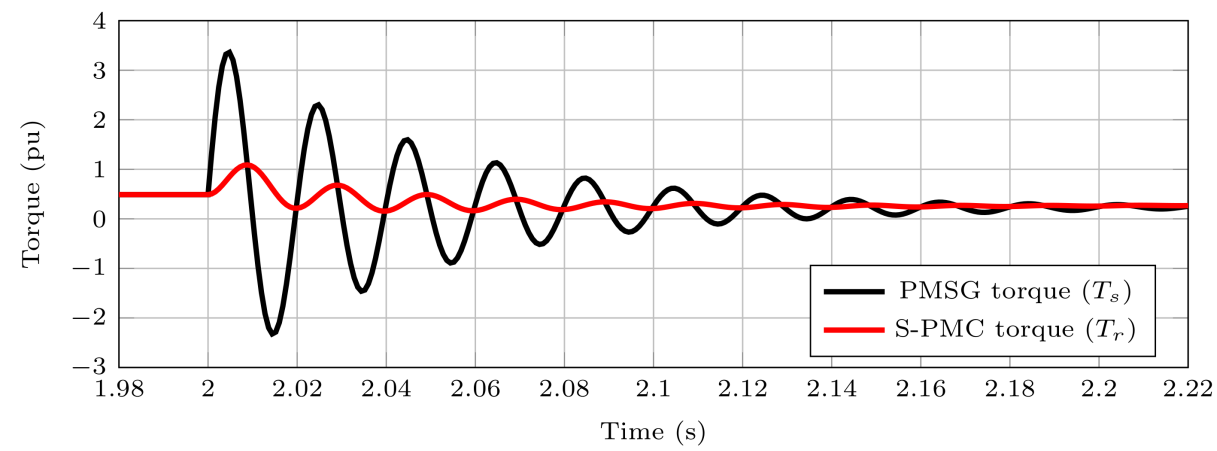

Figure 7. Short-circuit torque responses of the PSMG and the S-PMC during the time period $t=1.98$ $\mathrm{s}$ to $t=2.22 \mathrm{~s}$ of the LVRT event in Figure 6 .

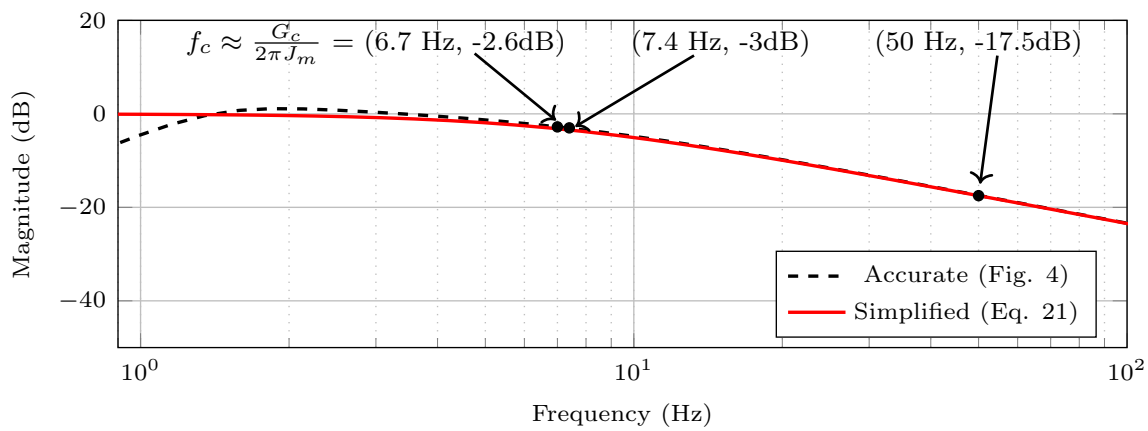

Figure 8. Frequency bode plot of the SS-WTS, where the bode plot as determined by Matlab/SIMULINK (Accurate) is given by the dashed line and the simplified transfer function of (21) is given by the solid line.

Figure 9 shows the three-phase short-circuit current response of the PMSG. It can be seen that, during the period $t=1.98$ to $2.24 \mathrm{~s}$, the SS-WTS produces a substantial steadystate, peak short-circuit current response of approximately 2.5 per-unit. The relatively large synchronous reactance (of the PMSG plus the SLR) results in the short-circuit current being sufficient to trip the grid protection relays while being low enough to avoid potential demagnetisation of the PMs. 


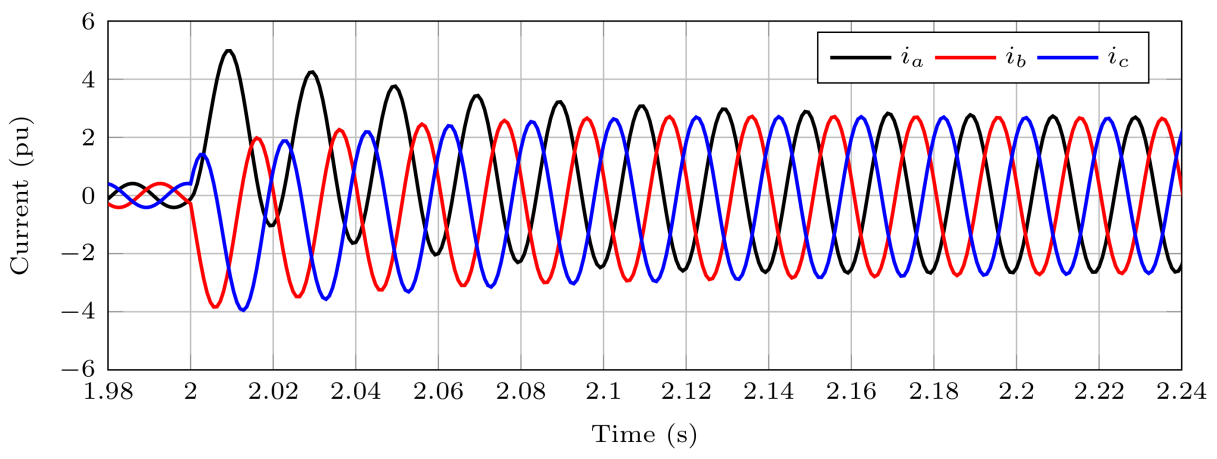

Figure 9. Short-circuit current response during the time period $t=0.98 \mathrm{~s}$ to $t=2.24 \mathrm{~s}$ of the LVRT event of Figure 6.

Figure 10 shows the power angle response of the SS-WTS during the LVRT event. It can be seen that the power angle remains far below $90^{\circ}$, which illustrates the stability of the direct grid-connected SS-WTS during the LVRT event of Figure 6.

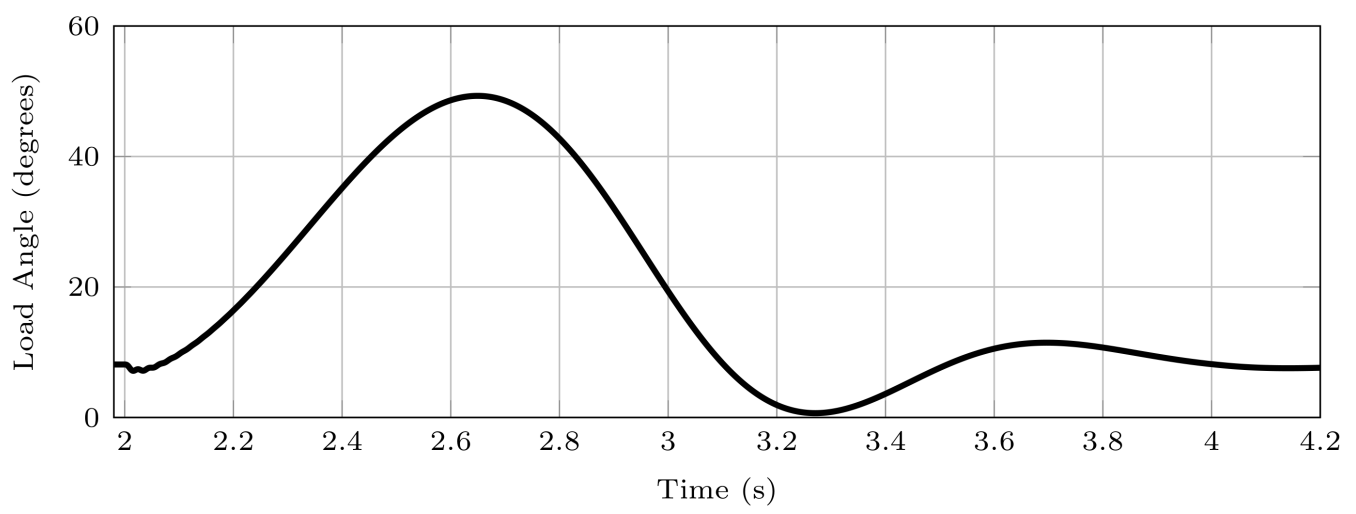

Figure 10. Load angle versus time during the LVRT event of Figure 6.

\subsection{Inertial Response}

Figure 11 shows the grid frequency response for a $5 \%$ loss of generating capacity $\left(\Delta P_{e}\right.$, see Figure 3) with and without the direct grid-connected SS-WTS. It can be seen that having the SS-WTS connected to the grid helps to reduce the rate of change of frequency (RoCoF), as well as to reduce the frequency nadir. This inherent primary frequency response of the direct grid-connected PMSG allows TSO more flexibility when it comes to bringing slower-acting regulating and contingency reserves online.

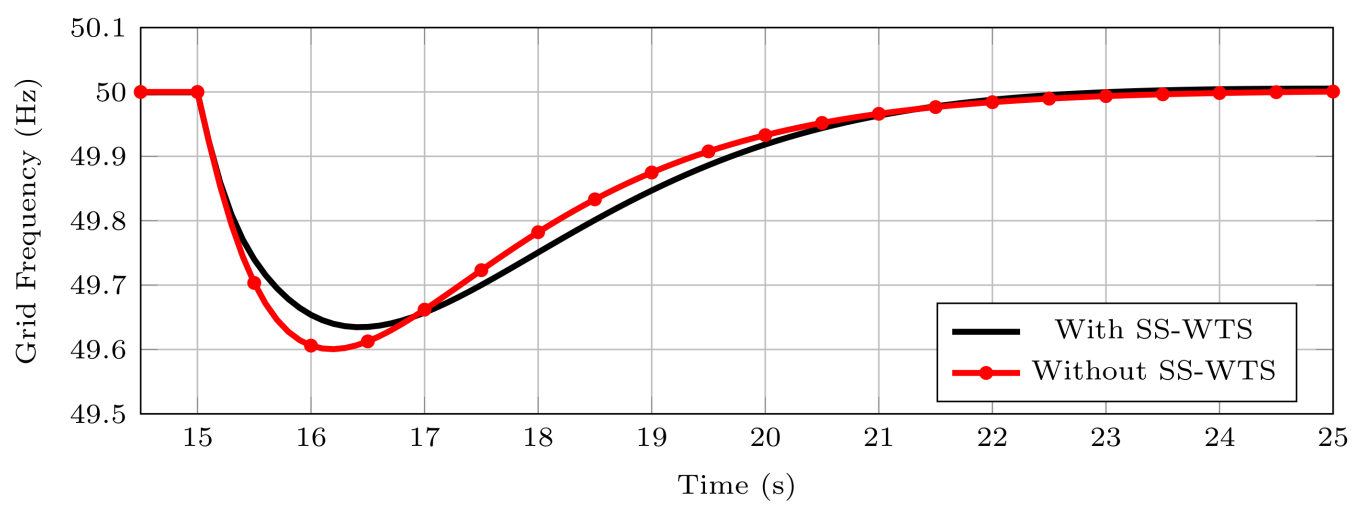

Figure 11. Grid frequency variation for a $5 \%$ loss of generating capacity $\left(\Delta P_{e}\right)$ with and without a SS-WTS connected to the grid. 


\subsection{Reactive Power Response}

Figure 12 shows the reactive power response of the SS-WTS for a $\pm 10 \%$ change in grid voltage, with supply power $\left(P_{S}\right)$ as a parameter. It can be seen that the SS-WTS provides an inherent form of corrective reactive power compensation to the grid when the grid voltage deviates from its nominal value. Furthermore, the relative change in reactive power response between $P_{S}=0.2 \mathrm{pu}$ and $P_{S}=1.0 \mathrm{pu}$ is $0.20 \mathrm{pu}$. However, if required, the degree of sensitivity of the PMSG's reactive power response to changes in grid voltage can be adjusted by changing the SLR, or the PMSG's induced back-emf voltage [35].

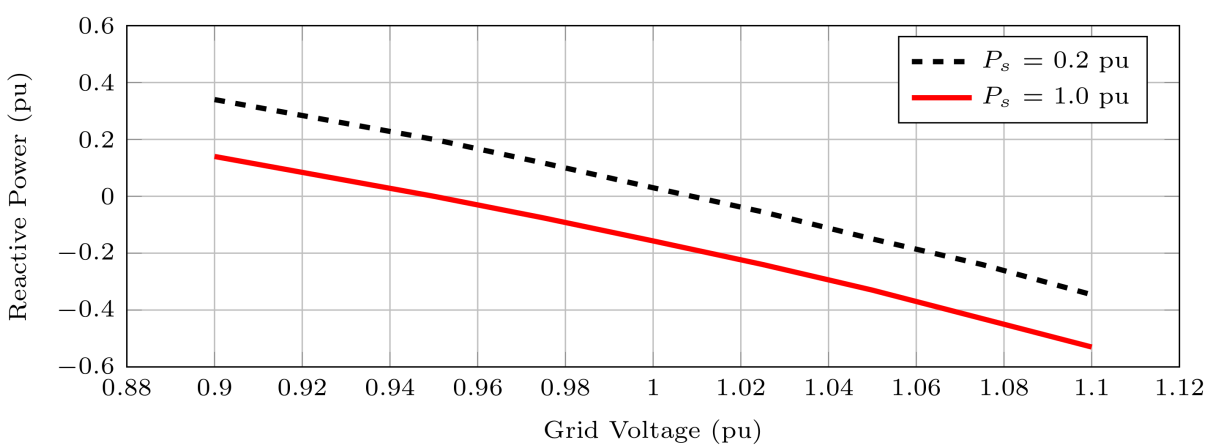

Figure 12. Steady-state reactive power versus grid voltage with supply power as a parameter.

\section{Discussion}

In this section, some of the design compromises when it comes to S-PMC gain versus efficiency and drivetrain speed versus cutoff frequency are discussed. Furthermore, the passive reactive power compensation of the SS-WTS is addressed.

\subsection{Slip versus Damping}

The S-PMC is shown to be effective at attenuating the large torque transients resulting from a LVRT event, a feature that is critical for extending the life cycle of a drivetrain gearbox. Moreover, (22) and consequently (23) indicate that increasing the selected rated slip value results in a greater degree of drivetrain damping at the cost of a lowered efficiency, as expressed in (6). Figure 13 shows bode diagram plots of the considered SS-WTS for three values of rated slip, and the corresponding S-PMC gain. It can be seen that increasing the rated slip to $\zeta=3 \%$ or $\zeta=5 \%$ (thus reducing the gain) has the effect of further attenuating the magnitude of the $50 \mathrm{~Hz}$ short-circuit torque. Additionally, Figure 13 shows that the frequency response for rated slip values of $3 \%$ and $5 \%$ has a narrower frequency passband $\left(f_{b}\right)$ range, of $2.8 \mathrm{~Hz}<f_{b}<4.2 \mathrm{~Hz}$, when compared to the case where $\varsigma=1 \%$, where the frequency passband range is $1 \mathrm{~Hz}<f_{b}<7.4 \mathrm{~Hz}$. There is thus a design trade-off between the value of rated slip and acceptable efficiency when it comes to attenuating both lower- and higher-order drivetrain frequencies. However, when considering that a WTS rarely operates at rated conditions, one may opt for larger rated slip values to narrow the passband frequencies and further dampen the $50 \mathrm{~Hz}$ transient torque of the PMSG.

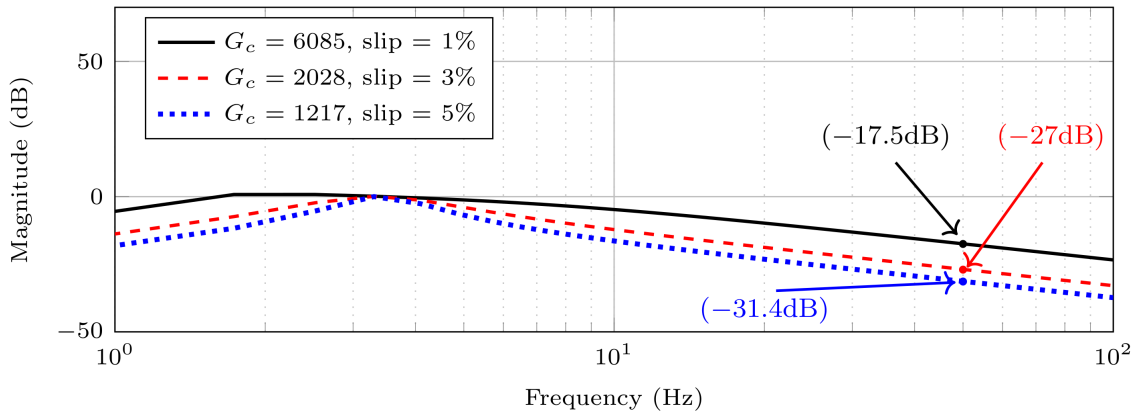

Figure 13. Frequency response with rated slip (and corresponding gain) a parameter. The inertia $\left(J_{m}\right)$ of the PMSG remained the same in the comparison. 


\subsection{Drivetrain Speed versus Damping}

The SS-WTS considered in this paper consists of a high-speed (HS) drivetrain that is categorised as having a generator speed range of between $600 \mathrm{rpm}$ and $2000 \mathrm{rpm}$. Mediumspeed (MS) drivetrains are categorised as having a speed range between $40 \mathrm{rpm}$ and $600 \mathrm{rpm}$. Table 2 compares the HS-WTS drivetrain considered here with two MS-WTS drivetrains with two different drivetrain speeds. The aspect ratio $(X)$ of the generators for the considered drivetrains is defined as

$$
X=\frac{L}{D}
$$

where $L$ is the axial length of the PM-rotor and $D$ is the air-gap diameter. The aspect ratio of the respective machines was used to determine suitable values for $D$ and $L$, based on dimensions found in $[36,37]$ for large-scale, geared PMSGs. The PM rotor was treated as a solid cylinder of which the inertia $\left(J_{m}\right)$ and volume $\left(V_{r}\right)$ respectively were determined by

$$
J_{m}=\frac{1}{32} \pi \rho L D^{4} \quad \text { and } \quad V_{r}=\frac{\pi}{4} D^{2} L,
$$

where $\rho=7700 \mathrm{~kg} \cdot \mathrm{m}^{-3}$ is the density of the rotor steel.

Considering the results in Table 2, low values for the cut-off frequency, $f_{c}$, are preferred, as they result in a greater attenuation of the $50 \mathrm{~Hz}$ short-circuit torque of the PMSG. It can be seen that the S-PMC gain $\left(G_{c}\right)$ increases more rapidly than the respective increase in rotor inertia as the rated WTS drivetrain speed decreases. Consequently, MS drivetrains have to operate at higher rated slip values (compared to HS drivetrains) to provide a comparable degree of attenuation to the short-circuit torque response of the PMSG. However, the choice of drivetrain speed has to be considered within the holistic design of the considered system, where factors such as cooling, overall efficiency, and system cost need to be considered.

\subsection{Reactive Power Compensation}

The SS-WTS considered in this paper is an uncontrolled system and the reactive power it absorbs or supplies consequently is directly dependent on, amongst others, the grid voltage, as shown in Figure 12. This uncontrolled system was selected for simplicity in deriving the modelling equations to illustrate the potential of direct grid-connected PMSGs to assist with important grid services, such as primary frequency response and short-circuit strength. Future SS-WTS technologies must include some degree of active reactive power compensation to be grid compliant, such as those considered in [22] and, more recently, in [23]. Notwithstanding this, the analytical model developed in this paper is directly applicable to future "hybrid" SS-PMSG designs.

Table 2. Comparison between the considered high-speed (HS) SS-WTS and two medium-speed (MS) SS-WTS drivetrains.

\begin{tabular}{cccc}
\hline & HS (1500 rpm) & MS (200 rpm) & MS (40 rpm) \\
\hline Aspect ratio $(X)$ & 1.14 & 0.31 & 0.23 \\
Volume $\left(\mathrm{m}^{3}\right)$ & 0.3 & 1.7 & 4.95 \\
S-PMC gain $\left(G_{c}, \varsigma=1 \%\right)$ & 6085 & 342,025 & $8,546,506$ \\
Inertia $\left(\mathrm{kg} \cdot \mathrm{m}^{2}\right)$ & 144 & 5911 & 85,724 \\
Cut-off frequency, $f_{c}(\mathrm{~Hz})$ & 6.7 & 9.2 & 15.9 \\
Attenuation, $A_{f}(\mathrm{~dB})$ & -17.5 & -14.7 & -9.95 \\
\hline
\end{tabular}

\section{Conclusions}

In this paper, the potential of direct grid-connected SS-WTS to provide essential grid services and withstand the subsequent additional mechanical loading was investigated. A transfer function model of a $1.5 \mathrm{MW}$, geared, direct grid-connected SS-WTS was derived and implemented in MATLAB/Simulink. This paper focuses on the dynamic response of 
an SS-WTS during a severe LVRT event and changes in the grid voltage. From the results, the following conclusions are drawn.

It was found that the S-PMC in the SS-WTS is capable of effectively damping the magnitude of the extreme short-circuit torque transients generated by the PMSG, a feature that is vital in extending the life cycle of the drivetrain components, specifically the drivetrain gearbox. Furthermore, the degree of damping is directly proportional to the selected rated slip (or inversly proportional to S-PMC gain, $G_{c}$ ); however, there is a trade-off between rated slip and the efficiency of the S-PMC.

Furthermore, it was found that higher-speed drivetrains provide a greater degree of damping (lower cut-off frequency, $f_{c}$ ) than lower-speed drivetrains. This is because the $\mathrm{S}$-PMC gain increases more rapidly than the rotor inertia of the generator as the drivetrain speed decreases.

The SS-WTS has the potential to increase the short-circuit strength of the grid while maintaining stability. The inherent ability of the SS-WTS to provide a primary frequency response to the grid in the event of a loss of generating capacity was also demonstrated.

The SS-WTS was shown to act as a passive reactive power compensator by supplying or absorbing reactive power in the events of a $\pm 10 \%$ change in grid voltage. Consequently, the SS-WTS is capable of providing grid services in the form of primary frequency response and reactive power compensation. The latter is even the case during periods of low wind speed, as it can then act as a synchronous condenser. This makes the SS-WTS an attractive renewable energy system, particularly in weaker areas of the grid.

The work presented in this paper demonstrates, analytically, the on-grid dynamic stability of a Type 1, direct grid-connected SS-WTS. However, future work with supporting measured results is required to verify the analytical modelling procedures and the results presented in this paper.

Author Contributions: Conceptualization, Formal analysis, Investigation, Methodology, Validation, Writing-original draft, Writing—review and editing, D.K.O. and M.K.; Data curation, software, D.K.O.; Funding acquisition, Resources, Supervision, M.K. All authors have read and agreed to the published version of the manuscript.

Conflicts of Interest: The authors declare no conflict of interest.

\section{References}

1. IEA. Renewables 2020_Analysis. Available online: https://www.iea.org/reports/renewables-2020 (accessed on 15 February 2021)

2. Global Wind Energy Council. Global Wind Report 2021. Available online: https://gwec.net/global-wind-report-2021/ (accessed on 24 March 2021).

3. Gloe, A.; Jauch, C.; Räther, T. Grid Support with Wind Turbines: The Case of the 2019 Blackout in Flensburg. Energies 2021, 14, 1697. [CrossRef]

4. Sourkounis, C.; Tourou, P. Grid Code Requirements for Wind Power Integration in Europe. Conf. Pap. Energy 2013, 2013, 437674. [CrossRef]

5. Wu, Y.-K.; Chang, S.-M.; Mandal, P. Grid-Connected Wind Power Plants: A Survey on the Integration Requirements in Modern Grid Codes. In Proceedings of the 2019 IEEE/IAS 55th Industrial and Commercial Power Systems Technical Conference, (ICPS), Calgary, AB, Canada, 5-8 May 2019; IEEE: Calgary, AB, Canada, 2019; pp. 1-9.

6. Denholm, P.L.; Sun, Y.; Mai, T.T. An Introduction to Grid Services: Concepts, Technical Requirements, and Provision from Wind; National Renewable Energy Laboratory: Golden, CO, USA, 2019.

7. Luo, X.; Wang, J.; Wojcik, J.D.; Wang, J.; Li, D.; Draganescu, M.; Li, Y.; Miao, S. Review of Voltage and Frequency Grid Code Specifications for Electrical Energy Storage Applications. Energies 2018, 11, 1070. [CrossRef]

8. Tu, S.; Zhang, B.; Jin, X. Research on DFIG-ES System to Enhance the Fast-Frequency Response Capability of Wind Farms. Energies 2019, 12, 3581. [CrossRef]

9. Díaz-González, F.; Hau, M.; Sumper, A.; Gomis-Bellmunt, O. Participation of Wind Power Plants in System Frequency Control: Review of Grid Code Requirements and Control Methods. Renew. Sustain. Energy Rev. 2014, 34, 551-564. [CrossRef]

10. Gevorgian, V.; Zhang, Y. Wind Generation Participation in Power System Frequency Response: Preprint. United States. Available online: https:/ / www.osti.gov/servlets/purl/1339349 (accessed on 25 April 2021).

11. Wu, Z.; Gao, W.; Gao, T.; Yan, W.; Zhang, H.; Yan, S.; Wang, X. State-of-the-art review on frequency response of wind power plants in power systems. J. Mod. Power Syst. Clean Energy 2018, 6, 1-16. [CrossRef] 
12. Dreidy, M.; Mokhlis, H.; Mekhilef, S. Inertia Response and Frequency Control Techniques for Renewable Energy Sources: A Review. Renew. Sustain. Energy Rev. 2017, 69, 144-155. [CrossRef]

13. Aho, J.; Buckspan, A.; Laks, J.; Fleming, P.; Jeong, Y.; Dunne, F.; Churchfield, M.; Pao, L.; Johnson, K. A Tutorial of Wind Turbine Control for Supporting Grid Frequency through Active Power Control. In Proceedings of the 2012 American Control Conference (ACC), Montreal, QC, Canada, 27-29 June 2012; IEEE: Montreal, QC, Canada, 2012; pp. 3120-3131.

14. De Rijcke, S.; Ergun, H.; Van Hertem, D.; Driesen, J. Grid Impact of Voltage Control and Reactive Power Support by Wind Turbines Equipped With Direct-Drive Synchronous Machines. IEEE Trans. Sustain. Energy 2012, 3, 890-898. [CrossRef]

15. Tang, R.; Luo, B.; Deng, X.; Shen, Y. Research on Reactive Power and Voltage Control for Wind Farm Based on coordinate control of DFIGs and SVG. Procedia Comput. Sci. 2020, 175, 460-467. [CrossRef]

16. Gonzalez-Longatt, F. Impact of Synthetic Inertia from Wind Power on the Protection/Control Schemes of Future Power Systems: Simulation Study. In Proceedings of the 11th IET International Conference on Developments in Power Systems Protection (DPSP 2012), Birmingham, UK, 23-26 April 2012.

17. Muljadi, E.; Samaan, N.; Gevorgian,V.; Li, J.; Pasupulati, S. Short circuit current contribution for different wind turbine generator types. In Proceedings of the IEEE PES General Meeting, Minneapolis, MN, USA, 25-29 July 2010; pp. 1-8.

18. Haddadi, A.; Farantatos, E.; Kocar, I.; Karaagac, U. Impact of Inverter Based Resources on System Protection. Energies 2021, 14, 1050. [CrossRef]

19. Jia, J.; Yang, G.; Nielsen, A.H.; Muljadi, E.; Weinreich-Jensen, P.; Gevorgian, V. Synchronous Condenser Allocation for Improving System Short Circuit Ratio. In Proceedings of the 2018 5th International Conference on Electric Power and Energy Conversion Systems (EPECS), Kitakyushu, Japan, 23-25 April 2018; pp. 1-5.

20. Potgieter, J.H.J.; Kamper, M.J. Design of New Concept Direct Grid-Connected Slip-Synchronous Permanent-Magnet Wind Generator. IEEE Trans. Ind. Appl. 2012, 48, 913-922. [CrossRef]

21. Potgieter, J.H.J.; Kamper, M.J. Design Optimization of Directly Grid-Connected PM Machines for Wind Energy Applications. IEEE Trans. Ind. Appl. 2015, 51, 2949-2958. [CrossRef]

22. Amuhaya, L.L.; Kamper, M.J. Design and optimisation of grid compliant variable-flux PM synchronous generator for wind turbine applications. In Proceedings of the 2015 IEEE Energy Conversion Congress and Exposition (ECCE), Montreal, QC, Canada, 20-24 September 2015; pp. 829-836. [CrossRef]

23. Ockhuis, D.K.; Kamper, M.J.; Loubser, A.T. Hybrid Excitation Method for Higher Pole Number Grid-Tie Synchronous Generators. In Proceedings of the 2020 IEEE Energy Conversion Congress and Exposition (ECCE), Detroit, MI, USA, 11-15 October 2020; pp. 1439-1446. [CrossRef]

24. Potgieter, J.H.J.; Kamper, M.J. Modeling and Stability Analysis of a Direct-Drive Direct-Grid Slip-Synchronous Permanent-Magnet Wind Generator. IEEE Trans. Ind. Appl. 2014, 50, 1738-1747. [CrossRef]

25. van Wyk, P.J.J.; Kamper, M.J. Simplified Analysis of Nonoverlap Short-Circuited Coil Winding Slip Permanent Magnet Couplers. IEEE Trans. Ind. Appl. 2016, 52, 4740-4751. [CrossRef]

26. Helsen, J.; Guo, Y.; Keller, J.; Guillaume, P. Experimental investigation of bearing slip in a wind turbine gearbox during a transient grid loss event. Wind Energy 2016, 19, 2255-2269. [CrossRef]

27. Molinas, M.; Suul, J.A.; Undeland, T. Extending the life of gear box in wind generators by smoothing transient torque with statcom. IEEE Trans. Ind. Electron. 2010, 57, 476-484. [CrossRef]

28. Licari, J.; Ugalde-Loo, C.E.; Ekanayake, J.B.; Jenkins, N. Damping of torsional vibrations in a variable-speed wind turbine. IEEE Trans. Energy Convers. 2013, 28, 172-180. [CrossRef]

29. Reder, M.D.; Gonzalez, E.; Melero, J.J. Wind Turbine Failures-Tackling Current Problems in Failure Data Analysis. J. Phys. Conf. Ser. 2016, 753, 072027. [CrossRef]

30. Saeedian, M.; Pournazarian, B.; Seyedalipour, S.S.; Eskandari, B.; Pouresmaeil, E. Emulating Rotational Inertia of Synchronous Machines by a New Control Technique in Grid-Interactive Converters. Sustainability 2020, 12, 5346. [CrossRef]

31. Lipo, T. Analysis of Synchronous Machines; CRC Press: Boca Raton, FL, USA, 2017.

32. Klontz, K.W.; Miller, T.J.E.; McGilp, M.I.; Karmaker, H.; Zhong, P. Short-Circuit Analysis of Permanent-Magnet Generators. IEEE Trans. Ind. Appl. 2011, 47, 1670-1680. [CrossRef]

33. El-Metwally, M.; El-Shimy, M.; Mohamed, A.; Elshahed, M.; Sayed, A. Reliability assessment of wind turbine operating concepts using reliability block diagrams (RBDs). In Proceedings of the Nineteenth International Middle East Power Systems Conference (MEPCON), Cairo, Egypt, 19-21 December 2017; pp. 430-436. [CrossRef]

34. Alhmoud, L.; Wang, B. A review of the state-of-the-art in wind energy reliability analysis. Renew. Sustain. Energy Rev. 2018, 81, 1643-1651. [CrossRef]

35. Ockhuis, D.; Kamper, M.J.; Loubser, A.T. Impedance Matching of Direct Grid-Connected Renewable Energy Synchronous Generators. In Proceedings of the International SAUPEC/RobMech/PRASA Conference, Cape Town, South Africa, 29-31 January 2020; pp. 1-6.

36. Polinder, H.; Van Der Pijl, F.F.A.; De Vilder, G.-J.; Tavner, P.J. Comparison of Direct-Drive and Geared Generator Concepts for Wind Turbines. IEEE Trans. Energy Convers. 2006, 21, 725-733. [CrossRef]

37. Xue,Y.; Han, L.; Li, H.; Xie, L. Optimal design and comparison of different PM synchronous generator systems for wind turbines. In Proceedings of the 2008 International Conference on Electrical Machines and Systems, Wuhan, China, 17-20 October 2008; pp. 2448-2453. 